\title{
PENGARUH MUSIK INSTRUMENTAL TERHADAP KUALITAS HIDUP PADA PASIEN GAGAL GINJAL KRONIK YANG MENJALANI HEMODIALISA
}

\author{
Tiarnida Nababan \\ Fakultas Keperawatan dan Kebidanan, Universitas Prima Indonesia \\ Email: tiarnidan@yahoo.com
}

\begin{abstract}
Chronic renal failure or late-stage renal disease is a progressive and irreversible disorder of renal function (the body fails in maintaining metabolism and balance of fluids and electrolytes), thereby causing uremia (retention of urea and other nitrogen waste in the blood). Treatment of kidney failure disease can be done by pharmacological and nonpharmacological means. Non-pharmacological treatment can be in the form of the provision of instrumental music. This study aims to find out the influence of instrumental music on quality of life in chronic kidney failure patients undergoing hemodialysis at the Royal Prima Hospital Medan. This type of research is pre-experimental research with a one-group pre-post-test design with the provision of instrumental music for 20 minutes. The population is 66 people and sampled as many as 20 people with accidental sampling techniques. The analysis used in using Wilcoxon test. Based on the calculation of the Wilcoxon signed-rank test, obtained $Z=-3,938$ with $(p=0.000)<0.05$, so it can be concluded that there is an instrumental music influence on the quality of life in chronic renal failure patients undergoing hemodialysis at Royal Prima Medan Hospital in 2018. It is recommended that instrumental music can be applied as an alternative therapy to improve the quality of life.
\end{abstract}

Keywords: chronic kidney failure, quality of life, instrumental music therapy

\section{PENDAHULUAN}

Ginjal merupakan organ yang memiliki kemampuan luar biasa. Hal ini disebabkan karena ginjal mampu menyaring zat-zat yang tidak terpakai (zat buangan) sisa metabolisme tubuh. Setiap hari, ginjal memproses darah dan menghasilkan sejumlah limbah serta ekstra cairan yang berlebih dalam bentuk urine. Selanjutnya, urin dialirkan menuju kandung kemih melalui ureter dan disimpan di dalam kandung kemih sebelum dikeluarkan saat buang air kecil (Adi, 2017).
Gagal ginjal kronik atau penyakit renal tahap akhir merupakan gangguan fungsi renal yang progresif dan irreversible (tubuh gagal dalam mempertahankan metabolisme dan keseimbangan cairan dan elektrolit), sehingga menyebabkan uremia (retensi urea dan sampah nitrogen lain dalam darah) (Smeltzer \& Bare, 2017). Seseorang membutuhkan dukungan dari keluarga untuk menjalani terapi hemodialisa, baik dukungan secara emosional, dukungan instrumental, dan dukungan informasi. Seseorang yang mendapatkan dukungan dari keluarga 
akan menjalani hemodialisa dengan penuh semangat (Rostanti, Bawotong, \& Onibala, 2016).

Hemodialisa merupakan suatu proses yang digunakan pada pasien dalam keadaan sakit akut dan memerlukan terapi dialisis jangka pendek (beberapa hari hingga beberapa minggu) atau pasien dengan penyakit ginjal stadium akhir atau end stage renal disease (ESRD) yang memerlukan terapi jangka panjang atau permanen (Suharyanto \& Majid, 2013). Terapi pengganti fungsi ginjal, seperti hemodialisis adalah perawatan medis rutin untuk penyakit ginjal kronis. Pasien melakukan terapi hemodialisis selama 4-5 jam. Pasien juga harus mengontrol gejala dan komplikasi dari penyakitnya. Hal ini berfungsi untuk meningkatkan kualitas hidup pasien gagal ginjal kronis (Hidayah, 2017).

Kualitas hidup seseorang ditentukan oleh individu itu sendiri, karena sifatnya sangat spesifik, dan bersifat abstrak, sulit diukur. Namun mengingat bahwa tujuan utama dari terapi paliatif adalah peningkatan kualitas hidup pasien, maka tenaga medis harus mampu menyikapi untuk memperoleh kualitas hidup yang diinginkan oleh penderita supaya dapat meraih dan mencapainya (Rasjidi, 2010).

Musik dapat menyebabkan perubahan pada tubuh kita secara fisik dan mental. Musik instrumental adalah suatu cara penanganan penyakit (pengobatan) dengan menggunakan nada atau suara yang semua instrument musik dihasilkan melalui alat musik disusun sedemikian rupa sehingga mengandung irama, lagu dan keharmonisan. Mekanisme kerja musik instrumental untuk relaksasi rangsangan atau unsur dan nada masuk ke canalis auditorius di hantar sampai thalamus sehingga memori dari sistem limbik aktif secara otomatis mempengaruhi saraf otonom yang disampaikan ke thalamus dan kelanjar hipofisis dan muncul respon terhadap emosional melalui feedback ke kelenjar adrenal untuk menekan pengeluaran hormon stress sehingga ses eorang menjadi rileks (Laily, Juanita, \& Siregar, 2014).

Hasil penelitian Global Burden of Disease tahun 2010, penyakit gagal ginjal kronis merupakan penyebab kematian peringkat ke-27 di dunia, tahun 1990 dan meningkat menjadi urutan ke-18 pada tahun 2010 (Kementerian Kesehatan RI, 2013). Hasil Riset Kesehatan Dasar tahun 2013 dan 2018 menunjukan bahwa prevalensi penyakit gagal ginjal kronis di Indonesia $\geq 15$ tahun berdasarkan diagnosis dokter pada tahun 2013 adalah $0,2 \%$ dan terjadi peningkatan pada tahun 2018 sebesar $0,38 \%$. Pada tahun 2015 kematian yang disebabkan karena gagal ginjal kronis 
mencapai 1.243 orang (Riskesdas, 2018).

Berdasarkan data Indonesian Renal Registry (2015) mengemukakan bahwa di Indonesia, jumlah pasien GGK yang mendaftar ke unit hemodialisis terus meningkat $10 \%$ setiap tahunnya. Prevalensi GGK diperkirakan mencapai 400 per 1 juta penduduk dan prevalensi pasien GGK yang menjalani hemodialisis mencapai 15.424 orang penduduk Indonesia.

Berdasarkan hasil survei awal melalui wawancara dengan kepala ruang Unit Hemodialisa menyatakan bahwa terdapat 66 orang pasien yang menjalani hemodialisa, baik satu minggu dua kali maupun satu minggu tiga kali dan lamanya hemodialisa minimal dalam seminggu selama 10 jam. Terdapat 46 orang pasien terlihat menurunnya kepatuhan pasien dalam menjalani jadwal hemodialisa dan motivasi pasien berkurang sehingga pasien lebih menutup diri, dan 20 orang pasien terlihat patuh dalam menjalani jadwal hemodialisa dan memiliki motivasi yang tinggi dalam menjalani hemodialisa.

\section{METODE}

Jenis penelitian ini adalah penelitian pra-eksperiment dengan menggunakan rancangan one-group pre post-test design. Penelitian ini, sebelum dilakukan terapi musik instrumental dengan menggunakan media player mp3 (pre-test) dilakukan pengukuran kualitas hidup pasien dengan kuesioner WHOQOL-BREF, kemudian diberikan intervensi terapi musik melalui relaksasi musik instrumental selama 12 kali (seminggu 3 kali) dengan durasi 20 menit tiap kali intervensi, setelah itu diukur kembali (post-test) dengan membagikan kuesioner kualitas hidup WHOQOL-BREF pada pasien gagal ginjal kronik tersebut.

Lokasi penelitian ini adalah di Unit Hemodialisa Rumah Sakit Royal Prima Medan, penelitian ini dilaksanakan selama 4 minggu. Populasi dalam penelitian ini adalah seluruh pasien gagal ginjal kronik yang menjalani terapi hemodialisa sebanyak 66 orang. Sampel yang diperoleh sebanyak 20 responden. Teknik pengambilan sampel menggunakan accidental sampling.

Persiapan alat-alat yang dibutuhkan dalam penelitian ini sebagai berikut: Alat-alat yang digunakan yaitu (1) Media player MP3 yang diiringi alunan musik instrumental; (2) Headset; (3) Jam tangan, dan (4) Alat tulis.

Data yang diperoleh dari responden secara langsung dengan menggunakan lembar observasi dan kuesioner WHOQOL-BREF untuk mengukur kualitas hidup. Dengan metode pertanyaan tanya jawab yang akan diajukan oleh peneliti kepada responden. 
Peneliti menekankan waktu pengukuran/observasi data variabel hanya pada satu kali pada satu saat (pretest), kemudian melakukan perlakuan musik instrumental sebanyak 12 kali intervensi dengan durasi 20 menit tiap intervensi sebanyak 3 kali dalam seminggu. Kemudian setelah intervensi sebanyak 12 kali sudah selesai dilakukan yaitu selama 4 minggu maka dilakukan kembali pengukuran dengan menggunakan kuesioner kualitas hidup WHOQOL-BREF (post test).

Analisa univariat dilakukan pada setiap variabel yang diteliti tujuannya melihat gambaran distribusi frekuensi sebelum dilakukan terapi musik melalui relaksasi musik instrumental (pre-test) dan setelah dilakukan terapi musik melalui relaksasi musik instrumental (post-test). Analisa bivariat untuk melihat perbedaan yang bermakna antara dua kelompok data (komparatif) yaitu varibel dependen (kualitas hidup) sebelum dilakukan terapi musik melalui relaksasi musik instrumental dan setelah dilakukan terapi musik melalui relaksasi musik instrumental dengan menggunakan uji Wilcoxon.

\section{HASIL DAN PEMBAHASAN}

\section{Hasil Penelitian}

Karakteristik responden pasien gagal ginjal kronik yang menjalani hemodialisa dapat dilihat pada tabel:

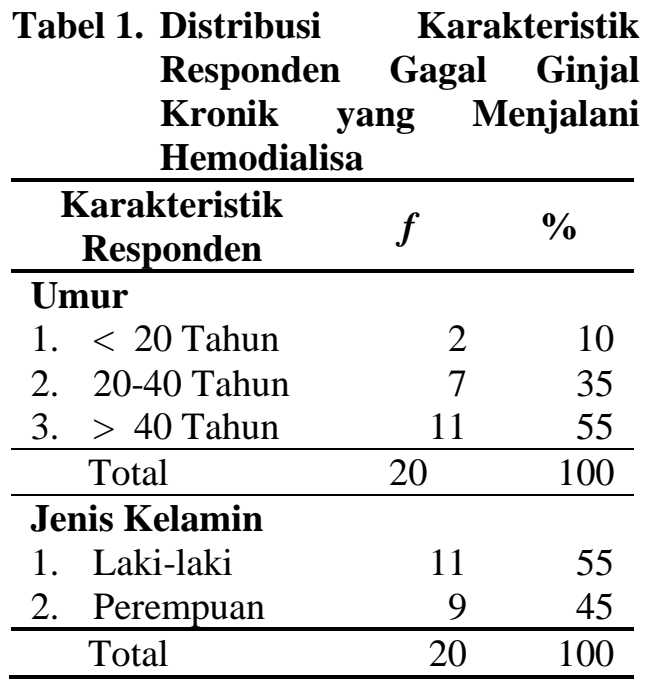

Berdasarkan Tabel 1 di atas menunjukkan bahwa karakteristik responden berdasarkan umur mayoritas berumur > 40 tahun sebanyak 11 orang $(55 \%)$, dan minoritas berumur $<20$ tahun sebanyak 2 orang (10\%). Berdasarkan jenis kelamin mayoritas laki-laki sebanyak 11 orang (55\%) dan minoritas perempuan sebanyak 9 orang $(45 \%)$.

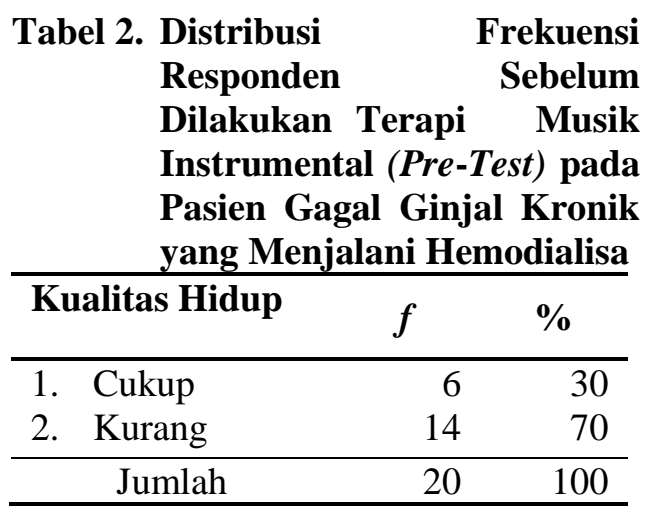

Berdasarkan Tabel 2 di atas dapat dilihat bahwa kualitas hidup pada pasien gagal ginjal kronik sebelum dilakukan terapi musik instrumental diketahui dari 20 orang responden, mayoritas responden mengalami kualitas hidup 
kurang yaitu sebanyak 14 orang (70\%), dan minoritas kualitas hidup cukup sebanyak 6 orang (30\%).

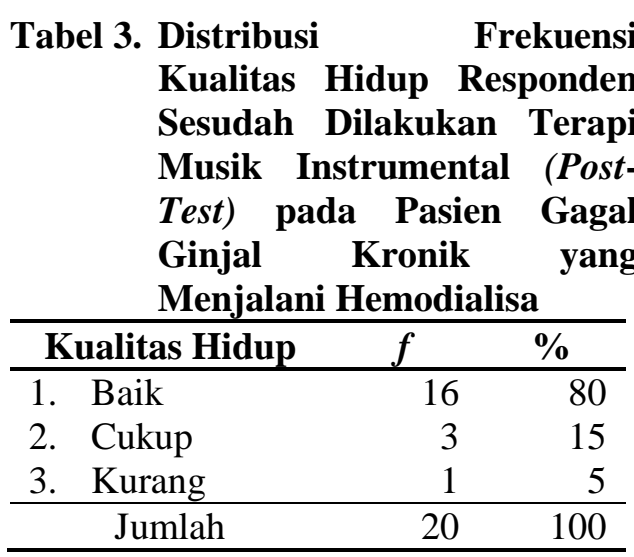

Berdasarkan Tabel 3 di atas dapat dilihat bahwa kualitas hidup pada pasien gagal ginjal kronik setelah dilakukan terapi musik instrumental dari 20 responden, mayoritas responden mengalami kualitas hidup baik sebanyak 16 orang $(80 \%)$, minoritas mengalami kualitas hidup kurang sebanyak 1 orang $(5 \%)$.

Tabel 4. Pengaruh Musik Instrumental Terhadap Kualitas Hidup pada Pasien Gagal Ginjal Kronik yang Menjalani Hemodialisa

\begin{tabular}{|c|c|c|c|c|c|c|c|}
\hline \multirow{2}{*}{$\begin{array}{l}\text { Terapi Musik } \\
\text { Instrumental }\end{array}$} & \multicolumn{3}{|c|}{ Kualitas Hidup } & \multirow{2}{*}{ Mean } & \multirow{2}{*}{$\begin{array}{c}\text { Std } \\
\text { Deviasi }\end{array}$} & \multirow{2}{*}{$Z$} & \multirow{2}{*}{$\begin{array}{c}p- \\
\text { Value }\end{array}$} \\
\hline & Baik & Cukup & Kurang & & & & \\
\hline 1. Pre-Test & 0 & 6 & 14 & 2,70 & 0,470 & $-3,938$ & 0,000 \\
\hline 2. Post-Test & 16 & 3 & 1 & 1,25 & 0,550 & & \\
\hline
\end{tabular}

Berdasarkan hasil Tabel 4 di atas dapat dilihat bahwa dari 20 orang pasien gagal ginjal kronik diketahui hasil perhitungan Wilcoxon signed rank test, diperoleh nilai $\mathrm{Z}=-3,938$ dengan $(\mathrm{p}=0,000)<0,05$ sehingga keputusan hipotesis maka $\mathrm{H}_{0}$ ditolak, yang berarti bahwa ada pengaruh terapi musik instrumental terhadap kualitas hidup pada pasien gagal ginjal kronik yang menjalani hemodialisa.

\section{Pembahasan}

\section{Karakteristik Responden}

Berdasarkan hasil penelitian yang dilakukan pada penderita gagal ginjal kronis diperoleh data sebanyak 20 penderita gagal ginjal kronis mayoritas berumur $>40$ thn sebanyak 11 orang (55\%) dan minoritas berumur $<20$ tahun sebanyak 2 orang $(10 \%)$. Penurunan fungsi ginjal merupakan proses normal bagi setiap manusia seiring dengan bertambahnya usia. Usia merupakan faktor resiko terjadinya gagal ginjal kronis. Semakin bertambah usia seseorang maka semakin berkurang fungsi ginjal.

Hasil penelitian ini didukung oleh penelitian Hartini (2016) yang menyatakan bahwa usia responden tertinggi berada pada rentang usia 51-60 tahun sebanyak 48 orang $(35,8 \%)$. Hal ini disebabkan karena semakin bertambah usia, semakin berkurang 
fungsi ginjal dan berhubungan dengan penurunan kecepatan ekskresi glomerulus dan memburuknya fungsi tubulus. Menurut asumsi peneliti bahwa usia berpengaruh terhadap kejadian GGK disebabkan semakin bertambah usia seseorang maka semakin berkurang fungsi ginjal. Secara normal penurunan fungsi ginjal ini telah terjadi pada usia diatas 40 tahun.

Berdasarkan hasil penelitian yang dilakukan di RS. Royal Prima pada penderita gagal ginjal kronis mayoritas laki-laki sebanyak 11 orang (55\%) dan minoritas perempuan sebanyak 9 orang (45\%). Menurut Adi (2017) menyatakan hipertensi sama dengan penyakit gagal ginjal kronis termasuk silent killer artinya penyakit yang diam tapi mematikan yang tidak menimbulkan gejala-gejala peringatan sebelumnya. Awalnya, penyakit ini bisa berawal dari hal- hal sepele misalnya dehidrasi atau kurang minum sehingga membuat tubuh rawan terkena infeksi saluran kemih. Kemudian kondisi tersebut berkembang menjadi infeksi ginjal.

Penelitian Hartini (2016) menyatakan penderita gagal ginjal kronik lebih banyak pada laki-laki. Laki-laki lebih rentan terkena gangguan ginjal dari pada wanita, seperti batu ginjal. Hal ini disebabkan karena kurangnya volume pada urin atau kelebihan senyawa (senyawa alami yang mengandung kalsium terdiri dari oxalate atau fosfat dan senyawa lain seperti uric acid dan amino acid cystine), pengaruh hormon, keadaan fisik dan intensitas aktivitas. Dimana saluran kemih pria yang lebih sempit membuat batu ginjal menjadi lebih sering tersumbat dan menyebabkan terjadi masalah pada ginjal.

Menurut asumsi peneliti bahwa jenis kelamin berpengaruh terhadap kejadian GGK. Dimana saluran kemih pria yang lebih sempit membuat batu ginjal menjadi lebih sering tersumbat dan menyebabkan terjadi masalah pada ginjal. Pola gaya hidup laki-laki lebih beresiko terkena GGK karena kebiasaan merokok dan minum alkohol yang menyebabkan ketegangan pada ginjal sehingga ginjal bekerja keras.

\section{Kualitas Hidup Responden Sebelum dilakukan Terapi Musik Instrumental}

Berdasarkan hasil penelitian yang dilakukan sebelum terapi musik Instrumental pada pasien gagal ginjal kronik yang menjalani hemodialisa mayoritas responden didapatkan pasien gagal ginjal kronik memiliki kualitas hidup kurang sebanyak 14 orang (70\%). Kualitas hidup adalah persepsi individu terhadap posisinya dalam kehidupan, dalam konteks budaya dan sistem nilai dimana individu tersebut hidup, dan hubungan terhadap tujuan, harapan, standar dan keinginan (World Health Organization, 2016). 
Pengalaman pasien hemodialisa dalam meningkatkan kualitas hidup menyatakan bahwa pasien yang melakukan hemodialisa mengalami masalah emosional. Pasien sering merasa tidak berdaya, merasa sedih, marah, takut, merasa bersalah, dan terisolasi. Selain masalah fisik dan dan psikologis, pasien hemodialisa juga mengalami gangguan sosial dan disfungsi seksual. Sehingga kualitas hidup pasien yang menjalani hemodialisa mengalami penurunan.

Menurut asumsi peneliti bahwa kualitas hidup berkaitan dengan pemberian musik instrumental. Ketika pasien dihadapkan pada musik secara langsung, tingkat cortisol mereka turun cukup drastis, sampai sekitar $40 \%$. Cortisol adalah hormon yang menyebabkan kita merasa tertekan. Dengan menurunnya tingkat cortisol, musik secara langsung membuat pasien merasa lebih baik. Oleh sebab itu, pasien sebelum dilakukan terapi musik instrumental, kualitas hidup pasien kurang.

\section{Kualitas Hidup Responden Setelah dilakukan Terapi Musik Instrumental}

Pemberian terapi musik diberikan setiap hari menjelang tidur ataupun pada saat beristirahat yaitu dengan memberikan terapi musik instrumental selama 45 menit selama 2 minggu (Laily, Juanita, \& Siregar, 2015).
Berdasarkan hasil penelitian yang dilakukan di RS Royal Prima Medan pada penderita gagal ginjal kronik yang menjalani hemodialisa sesudah dilakukan terapi musik instrumental mayoritas responden didapatkan pasien gagal ginjal kronik memiliki kualitas hidup baik sebanyak 16 orang (80\%).

Setelah dilakukan terapi musik instrumental terdapat 1 orang yang mengalami kualitas hidup kurang karena kondisi fisiknya sudah masuk dalam kategori buruk, ketergantungan pasien terhadap mesin hemodialisis seumur hidup menyebabkan tingkat kecemasan dan depresi pada pasien hemodialisis karena penyakit kronis yang dialami sehingga mengakibatkan ketakutan yang tinggi terhadap kematian. Setelah dilakukan musik instrumental terdapat 3 orang yang mengalami kualitas hidup cukup. Hal itu disebabkan karena kurangnya dukungan keluarga. Dukungan keluarga akan mempengaruhi kesehatan secara fisik dan psikologis, dimana dukungan keluarga tersebut dapat diberikan melalui dukungan emosional, informasi ataupun memberikan nasihat. Dukungan keluarga pada pasien gagal ginjal kronis yang menjalani hemodialisis terdiri dari dukungan instrumental, dukungan pengharapan dan dukungan harga diri yang diberikan sepanjang hidup pasien. 
Penelitian Hidayah (2017) laki-laki memiliki kualitas hidup yang lebih tinggi daripada perempuan karena perempuan dalam menghadapi masalah cenderung mudah mengalami stress emosional. Prevalensi gangguan psikologis seperti depresi dan kecemasan secara signifikan lebih tinggi pada perempuan dibandingkan laki-laki. Perempuan yang melakukan terapi hemodialisis umumnya memiliki kualitas hidup yang rendah dibandingkan laki-laki yang melakukan terapi hemodialisis.

Kualitas hidup pasien gagal ginjal dipengaruhi oleh durasi pengobatan hemodialisis. Lamanya pengobatan membuat pasien merasa khawatir. Hemodialisa dua kali seminggu lebih efektif dari tiga kali seminggu. Kualitas hidup yang lebih baik dikaitkan dengan peningkatan kelangsungan hidup dan kepatuhan pasien gagal ginjal terhadap terapi hemodialisis (Hidayah, 2017).

Menurut asumsi peneliti sesudah dilakukan musik instrumental memiliki kualitas hidup baik karena musik dapat menyebabkan perubahan pada tubuh kita secara fisik dan mental. Musik dapat menghilangkan kejenuhan pasien saat menjalani hemodialisa, karena hemodialisa memiliki proses yang panjang sekitar 4-5 jam di dalam ruangan. Saat pasien diberikan musik, pasien merasa lebih tenang, nyaman dan rileks menjalani proses hemodialisa tesebut.

\section{Pengaruh Musik Instrumental terhadap Kualitas Hidup pada pasien Gagal Ginjal Kronik yang menjalani Hemodialisa}

Berdasarkan hasil penelitian menunjukkan terjadi peningkatan kualitas hidup sebelum dan sesudah pemberian musik instrumental yaitu sebelum dilakukan terapi musik instrumental mayoritas responden didapatkan pasien gagal ginjal kronik memiliki kualitas hidup kurang sebanyak 14 orang (70 \%) dan sesudah dilakukan terapi musik instrumental mayoritas responden didapatkan pasien gagal ginjal kronik memiliki kualitas hidup baik sebanyak 16 orang (80\%).

Menurut asumsi peneliti ada pengaruh musik instrumental terhadap kualitas hidup pada pasien gagal ginjal kronik yang menjalani hemodialisa, karena ada perubahan kualitas hidup pada pasien gagal ginjal kronik sebelum dilakukan terapi musik instrumental dan setelah dilakukan musik instrumental. Musik dapat menstimulasi produksi neurotransmitter yang memberikan kenyamanan seperti endorphine. Pengeksposan dengan musik secara langsung dapat secara dramatis menurunkan hormon pembawa tekanan seperti kortisol. Sehingga dapat meningkatkan perasaan nyaman. 


\section{KESIMPULAN DAN SARAN}

\section{Kesimpulan}

Berdasarkan hasil penelitian didapatkan kesimpulan sebagai berikut:

1. Kualitas hidup pada pasien gagal ginjal kronik yang menjalani hemodialisa sebelum dilakukan terapi musik instrumental (pre-test), mayoritas responden memiliki kualitas hidup kurang.

2. Kualitas hidup pada pasien gagal ginjal kronik yang menjalani hemodialisa sesudah dilakukan terapi musik instrumental (post-test), mayoritas responden memiliki kualitas hidup baik.

3. Ada pengaruh musik instrumental terhadap kualitas hidup pada pasien gagal ginjal kronik yang menjalani hemodialisa di RS Royal Prima Medan.

\section{Saran}

\section{Bagi Unit Hemodialisa RS Royal Prima Medan}

Hasil penelitian ini agar dapat dimanfaatkan untuk meningkatkan pelayanan kesehatan pada pasien yang menderita penyakit terminal seperti gagal ginjal kronik di Unit Hemodialisa RS Royal Prima Medan.

\section{Bagi Responden}

Hasil penelitian ini diharapkan responden di Unit Hemodialisa RS Royal Prima Medan agar dapat dijadikan terapi musik sebagai terapi alternatif untuk meningkatkan kualitas hidup pasien gagal ginjal kronik.

\section{Bagi Peneliti Selanjutnya}

Hasil penelitian ini diharapkan menambah ilmu pengetahuan bagi peneliti dan agar dapat melakukan penelitian lebih dalam lagi mengenai domain-domain yang mempengaruhi kualitas hidup seperti domain fisik, domain psikologis, domain hubungan sosial dan lingkungan agar penderita gagal ginjal kronik yang menjalani hemodialisa melalui terapi musik instrumental di Unit Hemodialisa mengalami peningkatan kualitas hidup.

\section{DAFTAR PUSTAKA}

Adi, M. (2017). Serba serbi gagal ginjal. Yogyakarta: Diva Press.

Hartini, S. (2016). Gambaran karakteristik pasien gagal ginjal kronis yang menjalani hemodialisa di Rumah Sakit Umum Daerah dr. Moewardi.

Hidayah, N. (2017). Studi deskriptif kualitas hidup pasien penyakit ginjal kronik yang menjalani hemodialisis di rumah sakit PKU Muhammadiyah Yogyakarta. Jurnal Keperawatan Muhammadiyah.

Indonesian Renal Registry. (2015). Indonesia Renal Registry. Indonesian Renal Registry.

Kementerian Kesehatan RI. (2013). Laporan Hasil Riset Kesehatan Dasar (RISKESDAS) Nasional 2013. In Departemen Kesehatan Republik Indonesia.

Laily, E. I., Juanita, J., \& Siregar, C. T. (2015). Efektifitas Pemberian Terapi Musik Instrument Terhadap Kualitas Tidur Pasien Gagal Ginjal Kronik Yang Menjalani Hemodialisa 
[JOUR]. Idea Nursing Journal, 6(3), 45-50.

Laily, E. I., Juanita, \& Siregar, C. T. (2014). Efektifitas pemberian terapi musik instrument terhadap kualitas tidur pasien gagal ginjal kronik yang menjalani hemodialisa. Idea Nursing Journal, VI(3), 45-50.

Rasjidi, I. (2010). Perawatan paliatif suportif dan bebas nyeri pada kanker. Jakarta: Sagung Seto.

Riskesdas. (2018). Hasil Utama Riset Kesehatan Dasar. Kementrian Kesehatan Republik Indonesia. https://doi.org/1 Desember 2013

Rostanti, A., Bawotong, J., \& Onibala, F. (2016). Faktor faktor yang berhubungan dengan kepatuhan menjalani terapi hemodialisa pada penyakit ginjal kronik di ruangan Dahlia dan Melati RSUP Prof. Dr. R. D Kandou Manado. Jurnal Keperawatan UNSRAT.

Smeltzer, S. C., \& Bare, B. G. (2017). Keperawatan Medikal Bedah (Handbook for Brunner \& Suddarth's Textbook of Medical-Surgical Nursing). In Wolters Kluwe healthr.

Suharyanto, T., \& Majid, A. (2013). Asuhan keperawatan pada klien dengan gangguan sistem perkemihan. Jakarta: TIM.

World Health Organization. (2016). WHO Quality of Life-BREF (WHOQOL-BREF). 